\title{
Analysis of FKBP10, SERPINH1, and SERPINF1 genes in patients with osteogenesis imperfecta
}

\author{
C. Barbirato ${ }^{1,2}$, M. Trancozo ${ }^{1,2}$, M.R.G.O. Rebouçass ${ }^{3}$, V. Sipolatti ${ }^{3}$, \\ V.R.R. Nunes ${ }^{3}$ and F. Paula ${ }^{1,2}$ \\ ${ }^{1}$ Departamento de Ciências Biológicas, Núcleo de Genética Humana e Molecular, \\ Centro de Ciências Humanas e Naturais, Universidade Federal do Espírito Santo, \\ Campus de Maruípe, Vitória, ES, Brasil \\ ${ }^{2}$ Programa de Pós-Graduação em Biotecnologia, Rede Nordeste de Biotecnologia, \\ Centro de Ciências da Saúde, Universidade Federal do Espírito Santo, \\ Campus de Maruípe, Vitória, ES, Brasil \\ ${ }^{3}$ Hospital Infantil Nossa Senhora da Glória, Santa Lúcia, Vitória, ES, Brasil \\ Corresponding author: C. Barbirato \\ E-mail: clarabarbirato@yahoo.com.br
}

Genet. Mol. Res. 15 (3): gmr.15038665

Received March 29, 2016

Accepted May 31, 2016

Published September 2, 2016

DOI http://dx.doi.org/10.4238/gmr.15038665

Copyright $(C 2016$ The Authors. This is an open-access article distributed under the terms of the Creative Commons Attribution ShareAlike (CC BY-SA) 4.0 License.

ABSTRACT. Osteogenesis imperfecta (OI) is a heterogeneous disorder
that causes fragility, deformity, and fractures in bones. A large number
of genes that are associated with the disease have been identified in
the last decade; this makes the genetic diagnosis of OI more difficult.
To improve our knowledge of the genetic mutation profile in OI we
used single-stranded conformation polymorphism screening and
automated sequencing to investigate the SERPINH1, FKBPIO, and
SERPINF1 genes, which are related to recessive OI, in 23 unrelated
Brazilian patients. Nine rare changes and four common polymorphisms

Genetics and Molecular Research 15 (3): gmr.15038665 
were detected. Most changes were benign genetic variants. In general, changes in the SERPINH1 and SERPINF1 genes were synonymous polymorphisms or missense changes located in non-coding regions. A pathogenic change was found in the FKBP10 gene. The characterization of mutations related to OI in distinct populations can improve our knowledge of the genetic aspects of OI and help us develop molecular strategies for the diagnosis of the disease.

Key words: Recessive osteogenesis imperfecta; FKBP10; SERPINH1; SERPINF1

\section{INTRODUCTION}

Osteogenesis imperfecta (OI), also known as "brittle bone disease", is a clinically and genetically heterogeneous disorder that is mainly characterized by bone deformity and fragility; it leads to the frequent occurrence of fractures. Traditionally, OI is classified into OI types I (mild), II (lethal), III (severe, non-lethal), and IV (moderate) (Sillence et al., 1979). The Sillence classification was extended based on the identification of causative genes (Rauch and Glorieux, 2004).

In most cases, OI arises from autosomal dominant mutations in COL1A1 or COL1A2 genes that code for type I collagen, one of the most important proteins in bone, skin, and tendons (Barsh and Byers, 1981; Gajko-Galicka, 2002; Canty and Kadler, 2005). Recently, dominant autosomal mutations have also been detected in OI patients that carry genetic changes in the IFITM5 gene. This gene codes for an osteoblast-specific transmembrane protein that appears to be associated with bone mineralization (Moffatt et al., 2008; Cho et al., 2012; Semler et al., 2012).

The number of recessive cases in OI has increased significantly in the past few years. Thirteen genes have already been described to be targets of autosomal recessive mutations in OI: LEPREI (Cabral et al., 2007), CRTAP (Morello et al., 2006), PPIB (van Dijk et al., 2009), FKBP10 (Alanay et al., 2010), SERPINH1 (Christiansen et al., 2010), SERPINF1 (Becker et al., 2011), PLOD2 (Puig-Hervás et al., 2012), TMEM38B (Shaheen et al., 2012), BMP1 (Martínez-Glez et al., 2012), WNT1 (Fahiminiya et al., 2013), SP7 (Lapunzina et al., 2010), CREB3L1 (Symoens et al., 2013), and SPARC (Mendoza-Londono et al., 2015).

In general, most genes associated with recessive forms of OI are responsible for posttranslational modifications, assembling, folding, processing, or secretion of type I collagen. HSP47 (heat shock protein 47) and FKBP65 [an immunophilin found in the rough endoplasmic reticulum (RER)] are encoded by SERPINH1 and FKBP10, respectively, and act as molecular chaperones for type I procollagen, stabilizing the molecule in the RER, assisting in its folding, and preventing premature aggregation of its chains (Ishikawa et al., 2009). In addition, HSP47 and FKBP65 remain associated with type I procollagen during its transport from the RER to the Golgi apparatus, suggesting that the chaperones are also involved in procollagen type I secretion (Alanay et al., 2010). Deficient HSP47 or FKBP65 activity leads to the accumulation of type I procollagen in the cells and to a delayed secretion, without affecting synthesis and posttranslational modifications of the molecules (Alanay et al., 2010; Venturi et al., 2012a).

SERPINF1 encodes pigment epithelium-derived factor (PEDF) protein, a member of the serpins family, widely expressed in the brain, spinal cord, plasma, lungs, eyes, heart, and bones (Tucker et al., 2012). PEDF is a strong inhibitor of angiogenesis, and works by

Genetics and Molecular Research 15 (3): gmr.15038665 
suppressing endothelial cell migration and proliferation and induction of endothelial cell apoptosis (Quan et al., 2005). PEDF has a high affinity for the collagens that form the extracellular matrix (Venturi et al., 2012b). In bones, it regulates osteoprotegerin, which inhibits the maturation of osteoclasts, blocking proliferation and differentiation of the precursors of these cells. Thus, mutations that result in the loss of function in SERPINF1 lead to a reduction in the levels of osteoprotegerin, which can result in increased numbers of osteoclasts, and a consequent increase in bone resorption (Akiyama et al., 2010; Homan et al., 2011). Mutations in SERPINF1 have not been associated with defects in the synthesis, posttranslational modifications, or secretion of type I collagen but do lead to the development of severe phenotypes of OI.

Here, we present genetic alterations detected in SERPINH1, FKBP10, and SERPINF1 genes in a cohort of Brazilian OI patients. We identified potentially deleterious mutations and benign changes. Our results provide additional information about the mutational pattern of genes related to recessive OI.

\section{MATERIAL AND METHODS}

\section{Samples}

Clinical data and peripheral blood samples from 23 unrelated OI patients were collected at the Nossa Senhora da Glória Children's Hospital (HINSG), located in Vitória, a city in the southeast of Brazil. The probands were clinically diagnosed with OI according to the Sillence et al. (1979) classification. When available, samples from the patients' relatives were also analyzed. One hundred chromosomes from unaffected individuals of the same population were used for control samples.

This study was approved by the Research Ethics Committee of the HINSG and informed consent was obtained from all participants (Barbirato et al., 2015).

\section{Molecular analysis}

DNA was extracted from peripheral blood cells using the methodology described by Miller et al. (1988). Fragments containing the five exons of SERPINH1, the ten exons of FKBP10, the eight exons of SERPINF1, and the exon-intron boundaries were amplified by polymerase chain reaction (PCR) in a Veriti ${ }^{\circledR}$ 96-well thermal cycler (Applied Biosystems, USA). The primer sequences are available on request. The PCR products were screened for mutations by single-stranded conformation polymorphism (SSCP) on 5 and 7\% polyacrylamide, $5 \%$ glycerol gels and on $6 \%$ glycerol mutation detection enhancement gels (Cambrex Bio Science Rockland, Inc.) (Orita et al., 1989; Spinardi et al., 1991). Fragments showing abnormal migration patterns were sequenced to detect the variation in the patients' DNA sequences compared with the National Center for Biotechnology Information (NCBI) reference sequences NG_012052.1, NG_015860.1, and NG_028180.1 (for SERPINH1, FKBP10, and SERPINF1, respectively), and with mutations described by Dalgleish (1998) in the Human Collagen Mutation Database (Barbirato et al., 2015).

In previous studies, COL1A1 and COL1A2 genes of the same samples were analyzed through SSCP screening and automatic sequencing, and no mutations were detected. In a similar study, our group also analyzed LEPRE1, CRTAP, and PPIB genes and the results have already been published (Barbirato et al., 2015).

Genetics and Molecular Research 15 (3): gmr.15038665 


\section{RESULTS}

Nine rare changes were identified in FKBP10, SERPINH1, and SERPINF1 genes after the investigation of 23 patients with OI. The mutations detected are listed in Table 1. Moreover, four common polymorphisms of SERPINH1 and SERPINF1 were observed in high frequency in the control samples.

\section{Table 1. Genetic changes identified in patients with osteogenesis imperfecta (OI).}

\begin{tabular}{|c|c|c|c|c|c|c|c|}
\hline Number & Mutation & Gene & Type of mutation & Novel or known & Patient & Zygosity of mutation & OI type \\
\hline 1 & c. $590 \mathrm{~A}>\mathrm{G} /(\mathrm{p} . \mathrm{Lys} 197 \mathrm{Arg})$ & FKBP10 & Missense & Known & P.1 & Het & III \\
\hline 2 & c.831dupC & FKBP10 & Frameshift & Known & P. 2 & Hom & III \\
\hline \multirow[t]{2}{*}{$\frac{2}{3}$} & \multirow[t]{2}{*}{ c.1546G $>$ A/p.Leu516Phe } & \multirow[t]{2}{*}{ FKBP10 } & \multirow[t]{2}{*}{ Missense } & \multirow[t]{2}{*}{ Novel } & P.3 & Het & $\mathrm{I}$ \\
\hline & & & & & P.4 & Het & III \\
\hline 4 & c. $-190 \mathrm{~A}>\mathrm{G}$ & SERPINHI & Intronic region & Novel & P.5 & Het & IV \\
\hline 5 & c. $-211 \mathrm{G}>\mathrm{A}$ & SERPINHI & Intronic region & Novel & P.6 & Het & III \\
\hline 6 & c. $84+40 \mathrm{G}>A$ & SERPINF1 & Intronic region & Novel & P.7 & Het & III \\
\hline \multirow[t]{3}{*}{7} & \multirow[t]{3}{*}{ c. $643+82 \mathrm{~T}>\mathrm{C}$} & \multirow[t]{3}{*}{ SERPINF1 } & \multirow[t]{3}{*}{ Intronic region } & \multirow[t]{3}{*}{ Novel } & P.8 & Hom & I \\
\hline & & & & & P.9 & Hom & I \\
\hline & & & & & P.10 & Hom & III \\
\hline 8 & c. $18 \mathrm{~A}>\mathrm{G}(\mathrm{p}$. Leu6 $=)$ & SERPINF1 & Synonymous & Novel & P.1 & Het & III \\
\hline 9 & c. $21 \mathrm{C}>\mathrm{A}(\mathrm{p}$. Leu $7=)$ & SERPINF1 & Synonymous & Novel & P.1 & Het & III \\
\hline
\end{tabular}

Hom $=$ homozygosity; Het $=$ heterozygosity.

\section{FKBP10 gene}

Three distinct variations were detected in the FKBP 10 gene. The c.590A $>\mathrm{G}$ (p.Lys197Arg) mutation (Figure 1a) was found in the OI type III patient (P.1) in heterozygosis. P.1 was an isolated case: she was the daughter of an unaffected couple who reported no consanguinity. DNA from the patient's mother also had the same variant. DNA from her father was not available for analysis. Patient P.2 was an isolated case with a severe form of OI; the patient's parents reported no consanguinity. A duplicated cytosine (c.831dupC) in exon 5 in the homozygous state was detected in P.2 (Figure 1b). The heterozygous c.1546G $>$ A (p.Leu516Phe) change (Figure 1c) was detected in two patients with mild (P.3) and severe (P.4) OI. There was no information about the familial history of patient P.3. Patient P.4 had an affected sister and unaffected parents who reported absence of consanguinity. DNA from her father had the same variant. This change was absent in her affected sister and her mother.

\section{SERPINH1 gene}

Two changes were identified in the SERPINH1 gene. We detected two heterozygous genetic variations in the 5'-UTR region: c.-190A $>$ G (Figure 2a) in an OI type IV patient (P.5), and c.-211G $>$ A (Figure 2b) in an OI III patient (P.6). Both patients were isolated cases and reported no consanguinity.

Moreover, two non-pathogenic polymorphisms were detected in the SERPINH1 gene. The c.598C $>\mathrm{T}$ (p.Leu200=) change (Figure 2c) in exon 2, and the c.1011G $>$ A (p.Leu337=) synonymous change (Figure $2 \mathrm{~d}$ ) in exon 5 were found in 42 and $66 \%$ of control alleles, respectively. 


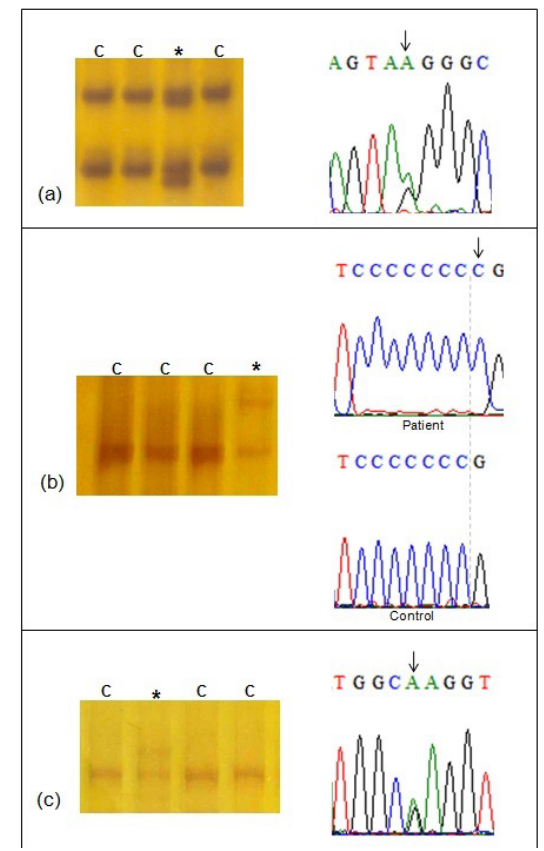

Figure 1. Single-stranded conformation polymorphism (SSCP) gels and sequencing of FKBP10 fragments. (a) c.590A > G/p.Lys197Arg; (b) c.831dupC; (c) c.1546G >A/p.Leu516Phe. *Abnormal fragments in SSCP gel, C = control samples, and the arrows point to the variants in the electropherograms.

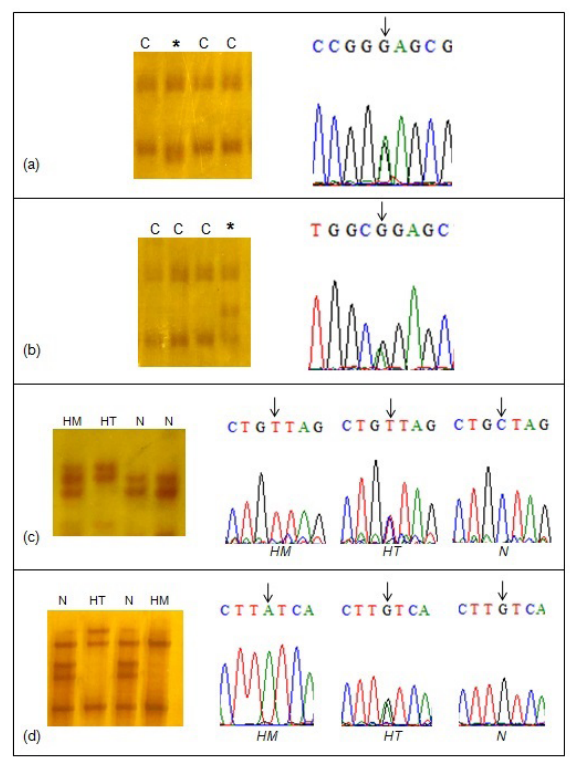

Figure 2. Single-stranded conformation polymorphism (SSCP) gels and sequencing of SERPINH1 fragments. (a) c. $-190 \mathrm{~A}>\mathrm{G}$; (b) c. $-211 \mathrm{G}>\mathrm{A}$; (c) c. $598 \mathrm{C}>\mathrm{T} / \mathrm{p} . \mathrm{Leu} 200=$; (d) c.1011G $>\mathrm{A} / \mathrm{p}$. Leu337=. HM $=$ homozygous state, HT $=$ heterozygous state, *abnormal fragments in SSCP gel, $\mathrm{C}=$ control samples and the arrows point to the variants in the electropherograms.

Genetics and Molecular Research 15 (3): gmr.15038665 


\section{SERPINF1 gene}

Four variants detected in the SERPINF1 gene were present in the OI patients. The heterozygous c.84+40G $>$ A change (Figure 3a) was found in an OI type III patient (P.7). P.7 was the daughter of a non-consanguineous couple, and she was an isolated case of OI in her family. The homozygous c.643+82T $>C$ genetic variation (Figure $3 b$ ) was detected in three unrelated cases (P.8, P.9, and P.10). Patients P.9 and P.10 were isolated cases in their families, but patient P.8 had an affected mother and sibling, suggesting autosomal dominant inheritance. The parents of patient P.9 reported that they were cousins, suggesting an autosomal recessive pattern. Hence, this change may not have been the causative mutation of OI in the presented patients. Patient P.1 and her unaffected mother carried two synonymous mutations in heterozygosity: the c.18A $>\mathrm{G}$ (p.Leu6=) change and the c.21C $>A(p . L e u 7=)$ genetic variation (Figure 3c).

We also detected two polymorphisms present in patients and control samples: the c.$86 \mathrm{C}>$ A intronic change (Figure $3 \mathrm{~d}$ ), and the c.963T $>\mathrm{C}(\mathrm{p}$. Tyr321=) synonymous polymorphism (Figure 3e), present in 50 and $40 \%$ of control alleles, respectively.

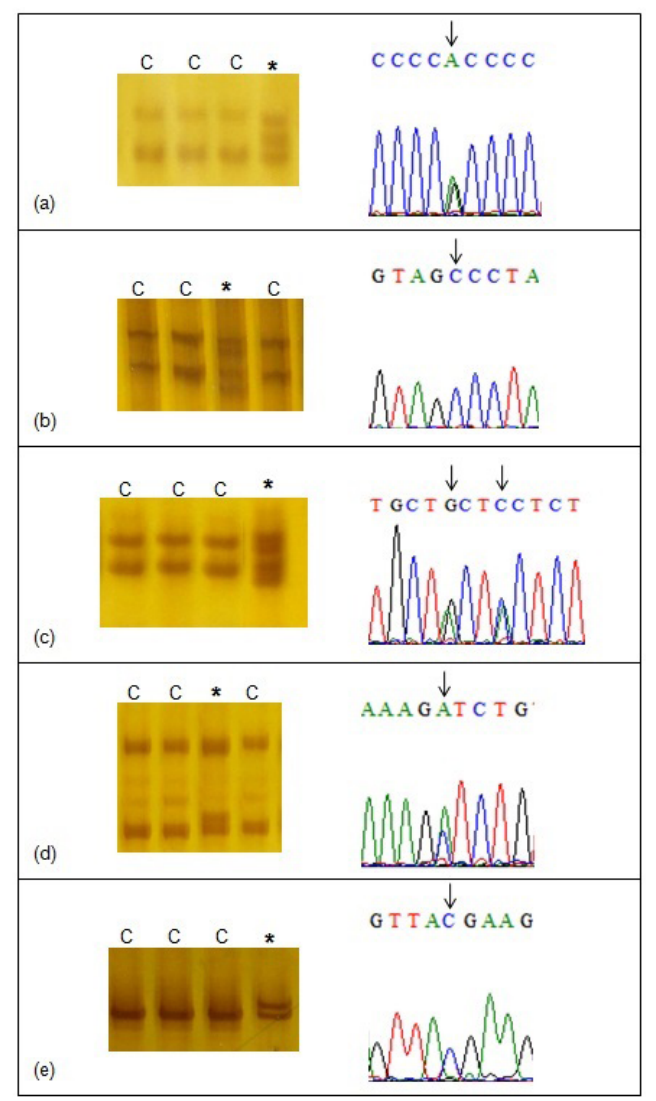

Figure 3. Single-stranded conformation polymorphism (SSCP) gels and sequencing of SERPINF1 fragments. (a) c. $84+40 \mathrm{G}>\mathrm{A}$; (b) c.643+82T $>$ C; (c) c. $18 \mathrm{~A}>\mathrm{G} / \mathrm{p}$. Leu6 $=$ and c.21C $>\mathrm{A} / \mathrm{p}$. Leu7 $=$; (d) c. $-86 \mathrm{C}>\mathrm{A} ;$ (e) c.963T $>\mathrm{C} / \mathrm{p}$. Tyr321=. *Abnormal fragments in SSCP gel, $\mathrm{C}=$ control samples, and the arrows point to the variants in the electropherograms.

Genetics and Molecular Research 15 (3): gmr.15038665 


\section{DISCUSSION}

Osteogenesis imperfecta is a bone disorder with relevant genetic heterogeneity, including recessive and dominant inheritance. To improve our knowledge of the mutation pattern in OI genes, we investigated FKBP10, SERPINH1, and SERPINF1, which are related to recessive OI, in 23 Brazilian patients. Nine rare genetic changes and four common polymorphisms were detected.

The proteins encoded by SERPINH1 and FKBP10 (HSP47 and FKBP65, respectively) act as molecular chaperones of type I collagen, and participate in stabilization, folding, prevention of premature aggregate formation, and secretion of the molecule (Ishikawa et al., 2009; Alanay et al., 2010). PEDF, encoded by the SERPINF1 gene, is associated with osteoclast maturation and bone resorption because it regulates osteoprotegerin (Akiyama et al., 2010; Homan et al., 2011). Mutations in FKBP10, SERPINH1, and SERPINF1 have been reported to cause recessive OI forms, resulting in affected type I collagen biosynthesis or an altered bone reabsorption rate.

The pathogenic c.831dupC duplication (exon 5) in the FKBP10 gene detected in patient P.2 has been reported previously (Dalgleish 1998; Alanay et al., 2010; Kelley et al., 2011; Shaheen et al., 2011; Caparrós-Martin et al., 2013; Schwarze et al., 2013). This mutation produces a translational frameshift (p.Gly278ArgfsX95) predicted to result in a stop codon and premature truncation of the protein. Absence of FKBP 65 cDNA in mRNA from skin fibroblasts of a patient carrying c.831dupC alleles indicates that the mutation results in null alleles (Alanay et al., 2010).

Two other rare changes were detected in heterozygosity in the FKBP10 gene. The c. $590 \mathrm{~A}>\mathrm{G}$ (p.Lys 197Arg) variation found in patient P.1 is predicted to be a benign change. The $1546 \mathrm{G}>\mathrm{A}$ (p.Leu516Phe) change detected in patients P.3 and P.4 is predicted to be potentially damaging in the African American and European American populations (Exome Variant Server from the NHLBI GO Exome Sequencing Project, last accessed in April, 2016) (Schwarz et al., 2014). However, this genetic variation was not detected in patient P.4's affected sister, suggesting that it is a non-pathogenic change.

We detected two changes in the SERPINH1 gene localized in the 5'-UTR region: the c.-211G $>$ A change, predicted as a polymorphism, and the c. $-190 \mathrm{~A}>\mathrm{G}$ change, detected in patient P.5 and predicted to be disease-causing (Schwarz et al., 2014). Indeed, 5'-UTR mutations have already been reported as the cause of diseases including OI (Cho et al., 2012; Semler et al., 2012; Shaheen et al., 2012, Caparrós-Martin et al., 2013). However, because the second mutation in patient P.5 was not identified, and this change is localized in a non-coding region, we suggest that the c.-190A $>\mathrm{G}$ change is not a disease-causing mutation.

Four rare changes were detected in the SERPINF1 gene. Two synonymous mutations $(\mathrm{c} .18 \mathrm{~A}>\mathrm{G} / \mathrm{p}$. Leu6 $=$ and $\mathrm{c} .21 \mathrm{C}>\mathrm{A} / \mathrm{p}$. Leu7 $=)$ were present in the heterozygous state in the same patient (P.1). These variants are predicted to be disease-causing (Schwarz et al., 2014). However, the patient's unaffected mother also carried both variants, suggesting that these are rare non-pathogenic changes. Two other changes were detected in the SERPINF1 gene: the heterozygous c. $84+40 \mathrm{G}>\mathrm{A}$ identified in patient P.7, and the homozygous c.643+82T $>\mathrm{C}$ detected in patients P.8, P.9, and P.10, predicted as polymorphisms (Schwarz et al., 2014). Moreover, SERPINH1 and SERPINF1 presented polymorphic changes in the control samples in significantly high percentages, and the majority of cases were synonymous variations.

In the present study, we did not detect causative mutations in the SERPINH1 gene

Genetics and Molecular Research 15 (3): gmr.15038665 
and there are few cases of reported mutations in SERPINH1 causing OI (Christiansen et al., 2010; Duran et al., 2015). Therefore, pathogenic changes in the SERPINH1 gene are thought to be very rare in OI patients. In contrast, an increasing number of authors describe causative mutations in the SERPINF1 gene, including the 19-bp deletion detected in two Brazilian OI patients (Minillo et al., 2014). Although we have detected four rare changes in the SERPINF1 gene, the prediction program and the pattern of inheritance suggest that they are not disease-causing variants. In FKBP10, we also identified two missense changes, probably non-pathogenic variations, and the homozygous c.831dupC frameshift mutation that causes a severe OI phenotype. Pathogenic changes in the FKBP10 gene have also been reported in distinct countries (Dalgleish, 1998), suggesting that pathogenic mutations in FKBP10 can be found in different populations.

In conclusion, we reported 13 mutations and polymorphisms in FKBP10, SERPINH1, and SERPINF1 genes; this work provides new information about the genetic aspects of recessive OI.

\section{Conflicts of interest}

The authors declare no conflict of interest.

\section{ACKNOWLEDGEMENTS}

Research supported by ArcelorMittal Tubarão, Fundação de Amparo à Pesquisa do Espírito Santo (FAPES), Fundo de Apoio à Ciência e Tecnologia do Município de VitóriaES (FACITEC), Universidade Federal do Espírito Santo (UFES) and Ministério da Ciência, Tecnologia e Inovação/Conselho Nacional de Desenvolvimento Científico e Tecnológico/ Ministério da Educação/Coordenação de Aperfeiçoamento de Pessoal de Nível Superior (MCTI/CNPq/MEC/CAPES). C. Barbirato was supported by a CAPES grant.

\section{REFERENCES}

Akiyama T, Dass CR, Shinoda Y, Kawano H, et al. (2010). PEDF regulates osteoclasts via osteoprotegerin and RANKL. Biochem. Biophys. Res. Commun. 391: 789-794.http://dx.doi.org/10.1016/j.bbrc.2009.11.139

Alanay Y, Avaygan H, Camacho N, Utine GE, et al. (2010). Mutations in the gene encoding the RER protein FKBP65 cause autosomal-recessive osteogenesis imperfecta. Am. J. Hum. Genet. 86: 551-559. http://dx.doi.org/10.1016/j. ajhg.2010.02.022

Barbirato C, Trancozo M, Almeida MG, Almeida LS, et al. (2015). Mutational characterization of the P3H1/CRTAP/CypB complex in recessive osteogenesis imperfecta. Genet. Mol. Res. 14: 15848-15858. http://dx.doi.org/10.4238/2015. December.1.36

Barsh GS and Byers PH (1981). Reduced secretion of structurally abnormal type I procollagen in a form of osteogenesis imperfecta. Proc. Natl. Acad. Sci. USA 78: 5142-5146.http://dx.doi.org/10.1073/pnas.78.8.5142

Becker J, Semler O, Gilissen C, Li Y, et al. (2011). Exome sequencing identifies truncating mutations in human SERPINF1 in autosomal-recessive osteogenesis imperfecta. Am. J. Hum. Genet. 88: 362-371. http://dx.doi.org/10.1016/j. ajhg.2011.01.015

Cabral WA, Chang W, Barnes AM, Weis M, et al. (2007). Prolyl 3-hydroxylase 1 deficiency causes a recessive metabolic bone disorder resembling lethal/severe osteogenesis imperfecta. Nat. Genet. 39: 359-365. http://dx.doi.org/10.1038/ ng1968

Canty EG and Kadler KE (2005). Procollagen trafficking, processing and fibrillogenesis. J. Cell Sci. 118: 1341-1353. http://dx.doi.org/10.1242/jcs.01731

Caparrós-Martin JA, Valencia M, Pulido V, Martínez-Glez V, et al. (2013). Clinical and molecular analysis in families with autosomal recessive osteogenesis imperfecta identifies mutations in five genes and suggests genotype-phenotype correlations. Am. J. Med. Genet. A. 161A: 1354-1369. http://dx.doi.org/10.1002/ajmg.a.35938

Genetics and Molecular Research 15 (3): gmr.15038665 
Cho TJ, Lee KE, Lee SK, Song SJ, et al. (2012). A single recurrent mutation in the $5 \phi$-UTR of IFITM5 causes osteogenesis imperfecta type V. Am. J. Hum. Genet. 91: 343-348. http://dx.doi.org/10.1016/j.ajhg.2012.06.005

Christiansen HE, Schwarze U, Pyott SM, AlSwaid A, et al. (2010). Homozygosity for a missense mutation in SERPINH1, which encodes the collagen chaperone protein HSP47, results in severe recessive osteogenesis imperfecta. Am. J. Hum. Genet. 86: 389-398. http://dx.doi.org/10.1016/j.ajhg.2010.01.034

Dalgleish R (1998). The human collagen mutation database 1998. Nucleic Acids Res. 26: 253-255. http://dx.doi. org/10.1093/nar/26.1.253

Duran I, Nevarez L, Sarukhanov A, Wu S, et al. (2015). HSP47 and FKBP65 cooperate in the synthesis of type I procollagen. Hum. Mol. Genet. 24: 1918-1928. http://dx.doi.org/10.1093/hmg/ddu608

Fahiminiya S, Majewski J, Mort J, Moffatt P, et al. (2013). Mutations in WNT1 are a cause of osteogenesis imperfecta. $J$. Med. Genet. 50: 345-348. http://dx.doi.org/10.1136/jmedgenet-2013-101567

Gajko-Galicka A (2002). Mutations in type I collagen genes resulting in osteogenesis imperfecta in humans. Acta Biochim. Pol. 49: 433-441.

Homan EP, Rauch F, Grafe I, Lietman C, et al. (2011). Mutations in SERPINF1 cause osteogenesis imperfecta type VI. $J$. Bone Miner. Res. 26: 2798-2803.http://dx.doi.org/10.1002/jbmr.487

Ishikawa Y, Wirz J, Vranka JA, Nagata K, et al. (2009). Biochemical characterization of the prolyl 3-hydroxylase 1.cartilage-associated protein.cyclophilin B complex. J. Biol. Chem. 284: 17641-17647. http://dx.doi.org/10.1074/ jbc.M109.007070

Kelley BP, Malfait F, Bonafe L, Baldridge D, et al. (2011). Mutations in FKBP10 cause recessive osteogenesis imperfecta and Bruck syndrome. J. Bone Miner. Res. 26: 666-672. http://dx.doi.org/10.1002/jbmr.250

Lapunzina P, Aglan M, Temtamy S, Caparrós-Martín JA, et al. (2010). Identification of a frameshift mutation in Osterix in a patient with recessive osteogenesis imperfecta. Am. J. Hum. Genet. 87: 110-114. http://dx.doi.org/10.1016/j. ajhg.2010.05.016

Martínez-Glez V, Valencia M, Caparrós-Martín JA, Aglan M, et al. (2012). Identification of a mutation causing deficient BMP1/mTLD proteolytic activity in autosomal recessive osteogenesis imperfecta. Hum. Mutat. 33: 343-350. http:// dx.doi.org/10.1002/humu.21647

Mendoza-Londono R, Fahiminiya S, Majewski J, Tétreault M, et al.; Care4Rare Canada Consortium (2015). Recessive osteogenesis imperfecta caused by missense mutations in SPARC. Am. J. Hum. Genet. 96: 979-985. http://dx.doi. org/10.1016/j.ajhg.2015.04.021

Miller SA, Dykes DD and Polesky HF (1988). A simple salting out procedure for extracting DNA from human nucleated cells. Nucleic Acids Res. 16: 1215. http://dx.doi.org/10.1093/nar/16.3.1215

Minillo RM, Sobreira N, de Faria Soares MdeF, Jurgens J, et al. (2014). Novel deletion of SERPINF1 causes autosomal recessive osteogenesis imperfecta type VI in two Brazilian families. Mol. Syndromol. 5: 268-275.

Moffatt P, Gaumond MH, Salois P, Sellin K, et al. (2008). Bril: a novel bone-specific modulator of mineralization. J. Bone Miner. Res. 23: 1497-1508. http://dx.doi.org/10.1359/jbmr.080412

Morello R, Bertin TK, Chen Y, Hicks J, et al. (2006). CRTAP is required for prolyl 3- hydroxylation and mutations cause recessive osteogenesis imperfecta. Cell 127: 291-304.http://dx.doi.org/10.1016/j.cell.2006.08.039

NHLBI GO Exome Sequencing Project. Exome Variant Server. Available at [http://evs.gs.washington.edu/EVS/]. Accessed April 26, 2016.

Orita M, Iwahana H, Kanazawa H, Hayashi K, et al. (1989). Detection of polymorphisms of human DNA by gel electrophoresis as single-strand conformation polymorphisms. Proc. Natl. Acad. Sci. USA 86: 2766-2770. http:// dx.doi.org/10.1073/pnas.86.8.2766

Puig-Hervás MT, Temtamy S, Aglan M, Valencia M, et al. (2012). Mutations in PLOD2 cause autosomal-recessive connective tissue disorders within the Bruck syndrome--osteogenesis imperfecta phenotypic spectrum. Hum. Mutat. 33: 1444-1449. http://dx.doi.org/10.1002/humu.22133

Quan GM, Ojaimi J, Li Y, Kartsogiannis V, et al. (2005). Localization of pigment epithelium-derived factor in growing mouse bone. Calcif. Tissue Int. 76: 146-153. http://dx.doi.org/10.1007/s00223-004-0068-2

Rauch F and Glorieux FH (2004). Osteogenesis imperfecta. Lancet 363: 1377-1385. http://dx.doi.org/10.1016/S0140$\underline{6736(04) 16051-0}$

Schwarz JM, Cooper DN, Schuelke M and Seelow D (2014). MutationTaster2: mutation prediction for the deep-sequencing age. Nat. Methods 11: 361-362. http://dx.doi.org/10.1038/nmeth.2890

Schwarze U, Cundy T, Pyott SM, Christiansen HE, et al. (2013). Mutations in FKBP10, which result in Bruck syndrome and recessive forms of osteogenesis imperfecta, inhibit the hydroxylation of telopeptide lysines in bone collagen. Hum. Mol. Genet. 22: 1-17. http://dx.doi.org/10.1093/hmg/dds371

Genetics and Molecular Research 15 (3): gmr.15038665 
Semler O, Garbes L, Keupp K, Swan D, et al. (2012). A mutation in the 5ф-UTR of IFITM5 creates an in-frame start codon and causes autosomal-dominant osteogenesis imperfecta type $\mathrm{V}$ with hyperplastic callus. Am. J. Hum. Genet. 91 : 349-357.http://dx.doi.org/10.1016/j.ajhg.2012.06.011

Shaheen R, Al-Owain M, Faqeih E, Al-Hashmi N, et al. (2011). Mutations in FKBP10 cause both Bruck syndrome and isolated osteogenesis imperfecta in humans. Am. J. Med. Genet. A. 155A: 1448-1452. http://dx.doi.org/10.1002/ ajmg.a.34025

Shaheen R, Alazami AM, Alshammari MJ, Faqeih E, et al. (2012). Study of autosomal recessive osteogenesis imperfecta in Arabia reveals a novel locus defined by TMEM38B mutation. J. Med. Genet. 49: 630-635. http://dx.doi.org/10.1136/ jmedgenet-2012-101142

Sillence DO, Senn A and Danks DM (1979). Genetic heterogeneity in osteogenesis imperfecta. J. Med. Genet. 16: 101116. http://dx.doi.org/10.1136/jmg.16.2.101

Spinardi L, Mazars R and Theillet C (1991). Protocols for an improved detection of point mutations by SSCP. Nucleic Acids Res. 19: 4009. http://dx.doi.org/10.1093/nar/19.14.4009

Symoens S, Malfait F, D’hondt S, Callewaert B, et al. (2013). Deficiency for the ER-stress transducer OASIS causes severe recessive osteogenesis imperfecta in humans. Orphanet J. Rare Dis. 8: 154. http://dx.doi.org/10.1186/1750$1172-8-154$

Tucker T, Nelson T, Sirrs S, Roughley P, et al. (2012). A co-occurrence of osteogenesis imperfecta type VI and cystinosis. Am. J. Med. Genet. A. 158A: 1422-1426. http://dx.doi.org/10.1002/ajmg.a.35319

van Dijk FS, Nesbitt IM, Zwikstra EH, Nikkels PG, et al. (2009). PPIB mutations cause severe osteogenesis imperfecta. Am. J. Hum. Genet. 85: 521-527. http://dx.doi.org/10.1016/j.ajhg.2009.09.001

Venturi G, Monti E, Dalle Carbonare L, Corradi M, et al. (2012a). A novel splicing mutation in FKBP10 causing osteogenesis imperfecta with a possible mineralization defect. Bone 50: 343-349. http://dx.doi.org/10.1016/j.bone.2011.10.023

Venturi G, Gandini A, Monti E, Dalle Carbonare L, et al. (2012b). Lack of expression of SERPINF1, the gene coding for pigment epithelium-derived factor, causes progressively deforming osteogenesis imperfecta with normal type I collagen. J. Bone Miner. Res. 27: 723-728. http://dx.doi.org/10.1002/jbmr.1480 